\title{
Pervivencias y resistencias paganas en los reinos anglosajones. Los alcances de la cristianización, siglos VI al VIII
}

Recibido: 03/02/2021. Aceptado: 21/09/2021.

\begin{abstract}
Resumen
La cristianización de los reinos anglosajones fue un proceso complejo, con avances y retrocesos. Durante el mismo, la Iglesia se vio obligada a elaborar diferentes estrategias para convertir a las élites y al campesinado dependiente vinculando elementos, sitios sagrados y prácticas paganas con las cristianas, lo que favoreció la reelaboración simbólica de las primeras. En este artículo pretendemos analizar las múltiples maneras en las que el paganismo anglosajón resistió y pervivió a través de las representaciones artísticas, los ritos, las tradiciones, los objetos y los textos hagiográficos, estos últimos elaborados para difundir el culto a los santos y atraer tanto donaciones como adeptos a las diferentes casas monacales que iban poblando aquel paisaje.
\end{abstract}

Palabras clave: reinos anglosajones, Iglesia, paganismo, cristianismo.

\section{Pagan Survival and Resistance in Anglo-Saxon Kingdoms. The Scope of Christianization, 6th to 8th Centuries}

\begin{abstract}
The Christianization of the Anglo-Saxon kingdoms was a complex process, characterized by advances and setbacks. During its course, the Church was forced to develop different strategies to convert the local elites and the subject peasantry by way of linking elements, sacred sites and pagan practices with Christian ones, favoring their symbolic modification. In this article, our aim is to analyze the multiple ways in which Anglo-Saxon paganism resisted and survived through artistic representations, rites, traditions, objects and hagiographic texts, these latter specifically elaborated to spread the cults of the saints, and to attract both donations and followers of the different monastic houses that were populating the landscape.
\end{abstract}

Keywords: Anglo-Saxon kingdoms, Church, paganism, Christianity. 


\section{Introducción}

Estudiar la historia de la sociedad altomedieval europea implica, en buena medida, analizar la expansión y consolidación del cristianismo como religión hegemónica. Los estudios recientes dedicados a este proceso hacen hincapié en la importancia de abordar este problema desde una perspectiva regional, que contemple la gran diversidad de características, interpretaciones dogmáticas y prácticas que surgieron desde los orígenes mismos de la cristiandad (Flechner y Mhaonaigh, 2016). Particularmente, las investigaciones sobre los cambios en las creencias, costumbres y ritos del Occidente europeo han estado vinculadas al análisis de la aceptación del cristianismo por los pueblos germanos. En este marco, los historiadores se han concentrado tradicionalmente en la interacción entre misioneros y poder político, dejando de lado las cuestiones étnicas, antropológicas y culturales de cada región. En los últimos años este posicionamiento ha evidenciado cambios sustanciales, especialmente porque la idea teleológica de progreso o transición en los estudios acerca de las conversiones ya no puede ser sostenida al momento de pensar la introducción del cristianismo en estos espacios.

Al contrario, se reconoce que en la Alta Edad Media el paganismo no fue erradicado rápidamente e incluso continuó su existencia: las prácticas paganas pudieron persistir en las comunidades cristianas, aunque algunas de ellas pudieran ser etiquetadas como "mágicas" o como "supersticiones" (Flechner y Mhaonaigh, 2016, p. 3). En todo caso, se plantea que la Iglesia se halló ante el desafío de diseñar estrategias adecuadas para convertir a las distintas poblaciones, a menudo vinculando elementos, festividades, sitios sagrados y prácticas paganas con las cristianas, lo que favoreció la reelaboración simbólica de aquellas.

1 Abreviaturas utilizadas: Greg I Ep = S. Gregorii Magni, Registrum Epistularum Libri VIII-XIV (Norberg, ed., 1982); HE = Historia Ecclesiastica Gentis Anglorum, Baedae De Venerabilis (Capps et. al., ed., 1930); PT = Poenitentiale Theodori (Charles-Edwards, 1995); VCA = Vita sancti Cuthberti s.auctore anonymo (Colgrave, 2007 [1940]); VCP= Vita sancti Cuthberti prosaica auctore Beda (Colgrave, 2007 [1940]); VG = Vita Sancti Guthlaci (Colgrave, 1956); VW= Vita Sancti Wilfrithi (Colgrave, 1927).

2 Son numerosos los estudios que abordan los conceptos de paganismo, magia y superstición. Entre los más destacados encontramos la obra de Valerie I. J. Flint, The Rise of Magic in Early Medieval Europe (1991), cuya definición sobre la magia incluye todo tipo de adivinaciones, prácticas sanadoras, el uso de amuletos, hierbas y encantamientos, así como la apelación a la demonología y la cosmología. Su objetivo en este libro es proporcionar una mirada nueva y diferente sobre las relaciones entre los fenómenos sobrenaturales y las personas que formaban parte de la sociedad cristiana de la Alta Edad Media. Se propone así demostrar cómo la Iglesia, a la vez que rechazaba toda forma de magia, entendía cuán importante era esta para los creyentes y de alguna manera procuró rescatarla incorporando algunas prácticas mágicas en el imaginario cristiano. Por su parte, Yitzhak Hen (1995) concuerda con los postulados de Flint, pero discute su aseveración respecto del “ascenso" de lo mágico durante la Alta Edad Media. Por el contrario, sostiene que la magia siempre estuvo presente, desde el mundo greco-romano (e inclusive antes) hasta la Edad Media. Entiende, además, que la idea de superstición o magia en un contexto cristiano puede considerarse como un sinónimo de religión no cristiana (ficta o falsa religio). Sostiene que para el siglo III se incorpora otro significado al término superstición, a partir de la etimología de superstes, referido a las supervivencias de las religiones paganas. Es interesante también la clasificación que propone Emilio Mitre (1995) al distinguir entre paganismo "de choque" y paganismo "subyacente", vinculando con el primero a aquellos pueblos germanos que entraron en las provincias imperiales sin haber recibido el arrianismo, entre quienes incluye a francos y anglosajones. El segundo, residiría en todo el conjunto de poblaciones, de diferente ascendencia étnica, a los que el autor llama cristianos nominales. La religión popular de esta masa es para el autor una religión plena de supersticiones, que coloca a todos los individuos en un nivel de creencias y de prácticas muy similar, sin distinción de categorías sociales. Además, estudios antropológicos como el de Silvia Alfayé Villa (2009) han contribuido a enriquecer las interpretaciones sobre estos conceptos, especialmente al establecer criterios para estudiar los rituales y cultos como actividad social materializada, entendiendo que deben ser estudiados en su propio contexto ideológico y material, tanto a nivel histórico-social, como desde micro perspectivas, desde el punto de vista arqueológico y espacial. Asimismo, son significativos los estudios de Marilyn Dunn (2009) para el caso anglosajón, así como el de Thomas M. Charles-Edwards (2008) y el de Lesley Abrams (2008) sobre los denominados “cristianismos celtas y germánicos”.

3 En este sentido, es interesante la mirada que Chris Wickham (2016) propone en relación a la idea de "conversión”. En primer lugar, entiende que es diferente de la adhesión: la mayoría de las cristianizaciones a gran escala han sido adhesiones, lo cual debe ser muy tenido en cuenta por el historiador al momento de analizar tales procesos. A este fenómeno, agrega el problema del avance del clero sobre la población laica en el intento de modificar sus prácticas y creencias en favor de la nueva religión. Otro problema que identifica el autor se refiere al hecho de oponer creencias frente al ritual: en general se verifica que las misiones tenían como objetivo principal la modificación de las creencias, pero que realmente tuvieron que comenzar por modificar los rituales. En cuarto lugar, el problema de la mediación: Wickham se pregunta quiénes toman las decisiones cuando una sociedad cambia su religión a través del 
El presente artículo pretende orientarse en el sentido de estas interpretaciones, sosteniendo, a la vez, que el paganismo anglosajón encontró durante el proceso de cristianización diferentes formas de persistir y resistir al avance del cristianismo a través de las representaciones artísticas, los ritos, las prácticas, los objetos y los textos hagiográficos. Haremos foco así en las circunstancias específicas de la otrora Britannia, que había conocido tempranamente el cristianismo en época romana pero que luego fuera progresivamente ocupada por los pueblos anglosajones. De esta manera, analizaremos de manera muy breve las particularidades que asumieron la conversión y la aceptación al cristianismo especialmente por parte de los sectores que no conformaban las élites de los reinos que se constituyeron en este espacio, así como ciertos aspectos de la reconfiguración de sus creencias y tradiciones. Intentaremos así brindar claridad a los siguientes interrogantes: ¿fue erradicado el paganismo de forma definitiva en este territorio? ¿Hubo resistencias al avance del cristianismo? Y si las hubo, ¿cómo se manifestaron?

Las fuentes de las que disponemos son esencialmente hagiográficas, aunque también haremos mención de otras de tipo arqueológico, analizadas por distintos autores. Estos escritos eclesiásticos son para el y la medievalista una documentación inigualable para la reconstrucción de las mentalidades ya que pueden considerarse la cristalización literaria de la conciencia colectiva (García de la Borbolla, 1999), entendida como aquella que una comunidad, iglesia o grupo tiene de sí misma y que se asocia a una figura o a un lugar al que pertenece el santo o la santa.

Sin embargo, si bien las fuentes documentales hagiográficas ofrecen datos para la reconstrucción del pasado histórico, los historiadores no deben perder de vista el hecho de que el autor del relato presenta una realidad histórica que ha sido tamizada por la visión personal de los hechos y que contribuye al embellecimiento y deformación de la verdad. En este sentido, resulta relevante comprender estos textos a través de la óptica que plantea Santiago Castellanos, es decir, a partir de las estructuras sociales e históricas de base desde las cuales emergieron, dado que estas explican su contenido y el mensaje que pretenden transmitir. $\mathrm{Al}$ abordar las hagiografías como hechos culturales propios de una época y no como productos casuales ni aleatorios el historiador se encuentra ante un desafío, ya que debe lidiar con una documentación altamente ideológica (Castellanos, 2004, p. 15).

Para el caso de las comunidades campesinas anglosajonas, las vitae de las que disponemos nos permiten entrever las relaciones entre estas y los misioneros, así como con los monasterios y sus representantes, sean obispos, abades o monjes. En estos relatos, dichas comunidades suelen presentarse como escenarios de la acción elaborada por los hagiógrafos, aunque de forma muy breve y puntual. Son frecuentes en los textos elementos como la alusión a las masas o multitudes que recurren al hombre santo, así como casos individuales. En consecuencia, las hagiografías proyectaron una imagen del santo que, tanto en vida como luego de su muerte, cohesionaba de alguna manera al grupo (Castellanos, 2004, pp. 82-83).

fomento de misioneros. Por su parte, Tomás Ó Carragáin y Sam Turner (2016), sostienen que la evidencia arqueológica e histórica sugiere que, en la mayoría de los casos, la decisión de las élites de abrazar la nueva religión fue rápidamente seguida por la conversión de algunos sectores de la sociedad. Sin embargo, podría considerarse que fue solo nominal. Afirman, por ejemplo, que si bien el bautismo pudo haber sido aceptado, fue mucho más difícil convencer a los recién bautizados de adoptar una identidad y práctica completamente cristiana, especialmente durante la Alta Edad Media. Además, esta realidad variaba entre las regiones, así como de acuerdo a distintos factores como las diferencias de género, edad o estatus social. Finalmente, Pablo Díaz (2003) coincide con esta perspectiva al afirmar que el proceso de cristianización vivenciado por el Imperio Romano durante el siglo IV no implicó necesariamente conversión individual. En la mayoría de los casos, la adopción del cristianismo no era acompañada de una renuncia total de las antiguas creencias así como de la asimilación consciente y profunda de una concepción totalmente diferente del mundo y de sus relaciones con él. 
Entendemos entonces que analizar estos documentos en la clave que propone Castellanos, ${ }^{4}$ como productos de una realidad social, económica y cultural propia, más allá de las limitaciones y características del género en particular, posibilitará nuestra aproximación a las problemáticas, resistencias y reacciones que suscitó el advenimiento de los misioneros a los diferentes reinos. Especialmente, creemos que pueden brindarnos herramientas para estudiar algunos aspectos de la relación que esta religión entabló con las comunidades rurales dependientes de las élites que fueron convertidas previamente.

\section{El paganismo anglosajón}

¿Qué entendemos por paganismo anglosajón? Para responder a este interrogante debemos establecer someramente cómo definimos superstición y paganismo, términos ambiguos y a menudo interrelacionados, cuyo uso frecuente atraviesa gran número de fuentes tardo-antiguas y medievales. En relación a las supersticiones, San Agustín de Hipona las define como aquellas creencias supervivientes que fueron abolidas por el cristianismo. ${ }^{5}$ En su concepción incluye todo tipo de ritos no cristianos, prácticas mágicas, astrológicas y de adivinación, es decir, aquellos fenómenos que Valerie Flint clasifica como magia (Flint, 1991). Por su parte, Yitzhak Hen entiende por "paganismo" lo que para el cristianismo latino significaba el término mores paganorum. Este era asignado a cualquier creencia, rito o práctica de una religión politeísta, ya fuera greco-romana, celta, teutónica, etc. Isidoro de Sevilla menciona otra acepción del término en referencia a los pagi: las zonas rurales en donde las personas establecían la práctica de rituales en bosques que se consideraban sagrados o la adoración de ídolos (Hen, 1995, p. 159). En este sentido, coincidimos con este autor en afirmar que, en algún modo, el concepto de paganismo se superpone con la idea de superstición, ya que ambos refieren a toda religión no cristiana.

Es frecuente la confusión entre estos términos, ya que su uso en las fuentes escritas en latín altomedieval europeo no fue estricto y consistente al momento de representar aquellos fenómenos que existían y persistían en la sociedad de entonces. Como señalamos, superstitio fue asociado a todo suceso espiritual y ritual que no fuese cristiano y del que se sospechara la intervención de una entidad diferente a la del Dios cristiano. Por su parte, el calificativo de "pagano" fue incorporado por las autoridades cristianas desde los tiempos de Agustín a aquellas prácticas que se vieran relacionadas con algún tipo de religión pagana, tanto griega o romana como germánica (Hen, 1995, p. 161).

En este marco, resulta interesante la perspectiva antropológica de Marilyn Dunn, quien plantea que el estudio de la cristianización de los anglosajones debe realizarse teniendo en cuenta la otredad, es decir a los pueblos que habitaban la isla (Dunn, 2009). Categoriza al cristianismo, junto con el islam y el budismo, entre las religiones que "rechazan al mundo" en pos de una mejor vida después de la muerte. Por el contrario, el paganismo anglosajón formaría parte del conjunto de religiones que "aceptan al mundo" y que se preocupan por el aquí y ahora: de asuntos tales como la salud, la prosperidad y la seguridad en esta vida, el bienestar de la familia, la prevención de una sequía o inundación o el almacenamiento seguro de una cosecha. A partir de estas consideraciones, Dunn sugiere que una de las mayores diferencias

4 Cabe señalar que este tema ha sido también trabajado por numerosos autores, empezando por los ya conocidos y clásicos estudios de H. Delehaye (1973), además de F. Baños Vallejo (1989), N. J. Higman (2014), P. Fouracre (1990), C. L. Watson (2004) y A. Thacker (2016), entre otros.

5 San Agustín, De Doctrina Christiana, II:XVII (27), II:XX-XXI(30-2), II:XXIII-XXIV(36-7); San Agustín, Enarrationes in Psalmos, 95:5-6. 
entre el cristianismo y el paganismo anglosajón radica en los distintos conceptos sobre la vida después de la muerte y sobre el destino y características de las almas. El cristianismo enseña que el individuo posee una sola alma que deja el cuerpo al momento de la muerte. En muchas culturas como la anglosajona, sin embargo, se creía que el cuerpo era habitado por dos o más espíritus o almas, mientras que la muerte era considerada como un proceso liminal en el cual una de las almas solamente podía llegar con seguridad a la otra vida luego de la ejecución de los rituales apropiados, la descomposición de la carne o ambas (Dunn, 2009, p. 6).

Otro aspecto de diferenciación radica en las deidades. Los anglosajones practicaban ritos y cultos de adoración politeístas que han sido relacionados con el panteón escandinavo a partir del material mitológico proveniente de tal región. Así, a través de este prisma y de la toponimia, se han vinculado los sitios sagrados del territorio que ocuparon a los nombres de Woden (Odín) y Thunor (Thor) (Dunn, 2009, pp. 57-59). También autores romanos como Tácito en su Germania han descrito cómo, antes de la llegada a Britannia, los anglos adoraban a Nerthus, diosa vinculada a la Madre Tierra (Terra Mater), aunque Dunn señala que en ocasiones aparece en las fuentes como un dios masculino identificado con la tierra. Era común asimismo la creencia en la existencia de diferentes deidades o seres sobrenaturales que interactuaban con los humanos en relación al control de la fertilidad y la naturaleza, además de deidades marinas y cuerpos celestes que se identificaban con estrellas. Como tales, habrían tenido una gran importancia en la vida cotidiana y el quehacer diario (Dunn, 2009, p. 69).

Sin embargo, las interacciones más frecuentes por parte de los anglosajones parecieran estar relacionadas con los elfos. Recientemente se ha establecido que estos se consideraban parecidos a los humanos, aparentemente masculinos, aunque en ocasiones manifestaban cambios de género. También se les confería el poder de infligir daños o enfermedades, así como la capacidad de ser una amenaza para aquellos miembros de las élites cuyos deseos eróticos transgredían los límites socialmente aceptados y ponían en peligro, de esta manera, el orden social. El elfo se nos presenta como un clásico ejemplo de un tipo de agente sobrenatural que adquiere un protagonismo importante en un sistema de creencias no doctrinal; se lo consideraba un ser de forma antropomórfica, con acceso completo a los deseos más profundos y las acciones secretas de los individuos (Dunn, 2009, p. 69).

En lo referente a la mitología y cosmología anglosajona, en su relato acerca de la victoria del rey Oswald de Northumbria sobre dos de sus rivales britanos, Beda ha brindado algunos indicios referentes a la creencia en la existencia de un valle o prado sagrado denominado Hefenfelth o Heavenfield. Este valle ha sido vinculado a la idea de una pradera celestial asociada con uno o más árboles sagrados, presente en las religiones germánicas y otras no cristianas (HE, III, 2). Dunn nos recuerda que The Creation Song en el poema anglosajón Beowulfse refiere a una planicie brillante rodeada por agua, mientras un disco giratorio, que se vincula con el movimiento circular del cosmos, es representado a veces por una esvástica, una decoración hallada en la joyería anglosajona y en urnas cinerarias (Dunn, 2009, p. 64). Por otra parte, el árbol del mundo o Yggdrasil juega un papel importante en la cosmología de los pueblos de Islandia, otro sitio que estuvo muy vinculado con los anglosajones. ${ }^{7}$ 
La evidencia toponímica, además, indica que en la Inglaterra anglosajona algunas características del ambiente natural fueron identificadas con divinidades específicas. Campos, valles, cuevas, lagunas, vertientes, bosques y árboles, especialmente robles, eran utilizados como lugares sagrados en donde se practicaban ritos y se realizaban diferentes sacrificios. Se cree que estos sitios sagrados conformaban una especie de red entre sí y que resultaban fundamentales para la vida agrícola, ya que esta era vinculada con los seres sobrenaturales que controlaban la tierra y, por lo tanto, la cosecha. En algunos de estos sitios se instalaban pequeñas plataformas de madera o casas en miniatura, mientras que otros eran fragmentos reutilizados de piedras o esculturas romanas que se disponían como altares. El uso de los mismos para ofrecer sacrificios para apaciguar o buscar el favor de la divinidad vinculada a la cosecha $u$ otras deidades tutelares era una parte fundamental del ritmo de la vida en una sociedad en donde nunca se estaba a salvo de las hambrunas (Dunn, 2009, p. 65).

De esta manera, el paganismo anglosajón invistió el paisaje, tanto natural como artificial, con una amplia complejidad de significados. La creencia en la sacralidad inherente a elementos naturales como rocas, árboles o pozos de agua, a los cuales se les atribuía poderes sanadores, resulta de una inmensa importancia para una sociedad en donde el conocimiento médico era prácticamente inexistente. En todo caso, los poderes de sanación se vinculaban con las mujeres, como lo atestiguan los restos de muchas de estas "sanadoras" que fueron hallados en sepulturas con pequeñas bolsitas colocadas alrededor del cuello que contenían diversos amuletos o eran utilizadas para conservar preparados y hierbas (Meaney, 1981, pp. 249-262).

Por otra parte, nos encontramos ante un territorio en el que las diosas y los dioses nativos habían sido asimilados durante varios siglos a un sistema que no solo los vinculaba con las divinidades romanas, sino que les daba una forma corporal similar con manifestaciones más etéreas. Según Barbara Yorke, cualquier asentamiento germánico con experiencia previa del Imperio Romano pudo haber estado familiarizado con el concepto de interpretatio romana, a través del cual tanto deidades como rituales germánicos y celtas fueron vinculados con el panteón romano (Yorke, 2003, p. $241 ; 2015)^{8}$. Como en otras provincias romanas, aún cuando el cristianismo ya había progresado en este territorio, lo había hecho con cierto nivel de integración a las prácticas existentes así como de apropiación de las representaciones simbólicas, como puede verse, por ejemplo, en los mosaicos al suroeste de Inglaterra, donde la figura tradicional de Orfeo aparece junto a iconografía cristiana (Yorke, 2003, p. 242). Asimismo, el símbolo de la cruz cristiana y la protección que ofrecía parece haber alcanzado una amplia distribución y aceptación para el siglo VI. Los objetos cristianos, señala Yorke, circulaban por la isla y eran enterrados en inhumaciones anglosajonas, particularmente en aquellas de alta connotación social.

Debemos tener en cuenta, además, que la fragmentación de Britannia tras su abandono hace que sea prácticamente imposible hablar de la cultura cristiana residual como una identidad homogénea. El posterior sometimiento de parte de esta provincia por los anglosajones propició un desarrollo religioso que siguió diferentes caminos. Aún en las zonas no ocupadas por los germanos, algunas áreas debieron haber sido más cristianas que otras. John Blair sostiene, por ejemplo, que el estuario del Severn tuvo una tradición romana establecida, mientras que las tierras al norte del muro de Adriano probablemente no fueron influenciadas significativamente hasta después de 400, o Cornwall hasta después de 500 (Blair, 2005, p. 13). Los cultos politeístas

8 En este sentido, un ejemplo de la asimilación entre el imaginario pagano clásico y el cristiano es el pasaje de la Vida de San Guthlac en el que se describe a San Bartolomé descendiendo del celestial Olimpo: “Illis vero veluti ad trudendum illum in praesentium tormentorum gehennas sese praecingentibus, ecce sanctus Bartholomaeus cum inmeso caelestis lucis splendore medias furvae noctis infuso lumine interrumpens tenebras, sese ab aethereis sedibus radiantis Olimpi coram illis aureo fulgore amictus obtulit”. VG, XXXII; 
romano-celtas no habían sido erradicados por completo y las fusiones sincréticas con el paganismo germánico tampoco fueron totales, lo que ha llevado a Blair a estudiar el territorio británico desde la concepción de una multiplicidad de experiencias culturales locales, en lugar de analizarlo por zonas inconexas, como habitualmente se hacía, con el énfasis puesto en la división este-oeste (Blair, 2005, p. 15).

En buena medida esa diversidad cultural fue enriquecida, además, por los habituales intercambios entre el continente y la isla. En la zona atlántica de Gran Bretaña abundan dos tipos de evidencia arqueológica periodizadas entre el siglo V y siglo VI: las inscripciones en piedra y la cerámica importada desde el Mediterráneo y la Galia occidental. La cerámica muestra que los habitantes de Cornwall, sur de Gales, Galloway y Argyll estaban en contacto, al menos de manera intermitente, con marinos y comerciantes de la Europa cristiana. Las inscripciones muestran que algunos habitantes de estas zonas fueron conmemorados con epitafios, a menudo de naturaleza cristiana explícita, haciendo uso de una tradición epigráfica anterior (Blair, 2005, p. 18).

No podemos pensar, entonces, en una situación homogénea a nivel de creencias y religiosidad. La realidad de la isla a la llegada de la misión enviada por Gregorio I en 597 mostraba un panorama diverso y múltiple en esta materia, lo que propició el despliegue de distintas estrategias por parte de la Iglesia para ganar nuevos fieles.

\section{Los alcances de la conversión}

Para poder analizar la interrelación entre paganismo y cristianismo, debemos aceptar que el cristianismo no era de ninguna manera homogéneo, monolítico y puro. En efecto, Peter Brown ha postulado que estamos ante un escenario religioso sumamente diverso que incluyó doctrinas, tradiciones, rituales y preceptos disímiles. Esta diferenciación tuvo que ver con un proceso de regionalización de las iglesias cristianas que se desarrolló para el siglo VII en los diferentes espacios alcanzados por la conversión. Tal proceso fue fruto de la decadencia de las redes comerciales del Mediterráneo y el fortalecimiento de las fronteras políticas y confesionales en el Cercano Oriente, lo que contribuyó a la conformación de un mosaico de "microcristiandades" adyacentes, pero distintas (Brown, 1997, p. 190).

Este panorama suscitó el cruce de diferentes interpretaciones por parte de los misioneros ya que todos decían practicar la "forma correcta" de cristianismo. Así aparecen en escena personajes como San Wilfredo (634-709), el primer sajón que llegaría a ser nombrado obispo de York, quien decía poseer ese conocimiento de las formas "correctas", romanas, del cristianismo. Por ejemplo, afirmaba conocer cómo debía realizarse la tonsura de los monjes y clérigos y cuál era el modo de fijar anualmente la fecha de la Pascua. En opinión de Brown, en realidad lo que Wilfredo se proponía era establecer su propia microcristiandad a partir de proclamar sus "verdaderos conocimientos" de las tradiciones romanas (Brown, 1997, p. 193).

Por otra parte, casos como el traslado opulento y público de los restos de San Cutberto a Lindisfarne, monasterio de doctrina irlandesa, en 690, nos sugieren la importancia de la competencia inter-monástica y de la necesidad de atraer adeptos, así como de vincularse con la población circundante. Esto resulta evidente cuando Beda en su Vita sancti Cuthberti relata que los sitios y objetos asociados con la vida, muerte y 
sepultura del santo atraían peregrinos de diferentes lugares: su tumba era considerada un espacio sagrado en donde se producían milagros y sanaciones (Blair, 2005, p. 148). En opinión de Blair, en este texto Beda recicla material que es reconocible como folklore vernáculo, otorgándole así coherencia narrativa y un propósito moral. De esta manera, el culto del santo y la tradición del monasterio se alojaban de cierta manera entre la cultura eclesiástica y la magia popular.

Nuevamente, la evidencia arqueológica, las hagiografías y otros documentos eclesiásticos como Poenitentiale Theodorio Iudicia Theodori, atribuido a Teodoro de Canterbury, constituyen fuentes fundamentales para interpretar lo que sucedía en los diferentes estratos sociales en relación a la nueva fe. En el caso de los penitenciales, se pueden ubicar los primeros ejemplos de este tipo de textos en Irlanda y en Gales entre finales del siglo V y el siglo VI (Oakley, 1940). Sin embargo, se considera que podrían haber existido con anterioridad a esta datación, la cual corresponde a la de los primeros documentos que se vinculan con certeza al género como algunos escritos de San Patricio y otros influenciados por San David en sínodos galeses (Neyra, 2006). Se trataba de manuales de penitencia que contenían largos programas, listados, tarifas o penas específicas correspondientes a diferentes tipos de pecados. De este modo, establecían qué conductas eran consideradas pecados y cómo obtener el perdón. Si bien aún en la Alta Edad Media no se establecía la diferencia entre pecado capital y pecado venial, a partir de la difusión de estos textos la penitencia comienza a cuantificarse, es decir, la pena empieza a ser tasada en proporción a la gravedad de la falta ante Dios (Neyra, 2006). Desde el siglo VII en adelante, los libros penitenciales fueron reproducidos en los reinos anglosajones y progresivamente, con el correr de los siglos, en el continente y en Islandia.

Un aspecto importante a tener en cuenta respecto de estas fuentes es que muchas de ellas, como el caso de Iudicia Theodori, son de dudosa procedencia y autoría (Oakley, 1940). Este manuscrito estaría basado en los juicios de Teodoro de Canterbury, conocido también como Teodoro de Tarso, si bien no fuera escrito por sus manos. La versión más conocida de esta fuente es la llamada "U" o Discipulus Umbrensium, quien a su vez lo habría copiado del penitencial de Cominianus (Cummean en inglés) escrito en Irlanda presumiblemente en 650 (O'Loughlin y Conrad-O'Briain, 1993).

En relación a los registros materiales, asistimos a un proceso de cambios lentos y graduales, que se evidencian, por ejemplo, en los ritos funerarios. El bautismo era requerido para todos los creyentes, pero la "cristiana sepultura" no había sido prescripta con claridad: era un privilegio más que una obligación. La forma y la ubicación de la tumba probablemente transmitían asociaciones jerárquicas y ancestrales a las cuales era muy difícil renunciar por parte de los creyentes y, en la práctica, esto ocurrió muy lentamente. De este modo debemos tener en cuenta que el valor de las prácticas funerarias como evidencia directa de conversión es bastante limitada.

Se ha extendido la suposición de que el cristianismo romano prohibió a los conversos ser enterrados entre sus ancestros o depositar objetos en sus tumbas, pero la misma carece de sustento. Ningún pronunciamiento conocido del papado prohibió ajuares en tumbas y las sepulturas en iglesias y camposantos eran prácticas establecidas en el mundo franco. En este sentido, John Blair cita estudios recientes que han enfatizado que la declinación creciente de los ajuares funerarios y la adopción de un enterramiento orientado a santuarios pudo haberse debido más bien a causas económicas y culturales que a religiosas (Blair, 2005, p. 59). Si los enterramientos con objetos en este período raramente pueden decirnos que la población era cristiana, tampoco pueden asegurarnos que fuera pagana. A la vez, no hay evidencias anteriores a 670 en el territorio anglosajón, fuera de la familia real de Kent, de que cristianos laicos 
tuviesen la expectativa de yacer en suelo sagrado cerca de las iglesias, ni de que se permitiese que la nueva fe socavase las expresiones funerarias tradicionales de parentesco, comunidad y estatus.

Con este posicionamiento coincide Sally Crawford, quien también desde una perspectiva arqueológica ha señalado que, si bien se verifican cambios en los ritos funerarios hacia el siglo VII, con la progresiva desaparición de los ajuares en las tumbas y el sucesivo establecimiento de enterramientos en camposantos, no hay evidencias de que la temprana iglesia anglosajona haya tomado medidas concretas para suprimir o condenar el depósito de objetos junto a los difuntos (Crawford, 2004, pp. 87-102). En todo caso, sostiene que esta problemática es aún materia de debate. Esto se debe a que existe un importante número de tumbas con ajuares denominadas de "Fase Final" que plantean interrogantes y varios problemas de interpretación. Las mismas se encuentran en el período de transición entre el paganismo y el cristianismo, por lo que se discute la naturaleza de las creencias religiosas de los individuos allí depositados.

Coincidimos con la autora en que la ubicación de estas tumbas lejos de las iglesias, a veces en cementerios ancestrales, a veces en túmulos, con ajuares a menudo lujosos, implica continuidad o identidad con un pasado tradicional pagano. El montaje de estos enterramientos es muy diferente en cantidad y carácter de aquellos en los primeros cementerios anglosajones, y muchos de los ajuares, especialmente en tumbas de mujeres, parecieran ser explícitamente cristianos en su simbolismo (Crawford, 2004, p. 91).

En estas sepulturas femeninas se ha encontrado joyería cruciforme, con diseños evidentemente cristianos, aunque Crawford indica que esto no significa necesariamente que quien los usara practicara la nueva religión. De hecho, muchos de estos objetos eran aquellos mencionados anteriormente: pequeños sacos, bolsas o contenedores de diferentes elementos como hierbas o retazos de telas finas, que en algunos casos llevaban etiquetas, broches o prendedores. Dentro de ellos, además, se colocaban habitualmente dientes de caballos, perros, lobos, bueyes o jabalíes. También se han encontrado valvas de cauri, de mayor utilización para el siglo VII. Posteriormente, se utilizaron pendientes realizados con dientes de castor, en su mayoría montados en oro o en aleación de cobre. Su uso fue más ritual que funcional y posiblemente como relicarios bajo la influencia cristiana (Blair, 2005, p. 172).

Además, el frecuente intercambio con el continente permitió, para el siglo VII, la adopción de modas como parte de un patrón de competencia y emulación de las mujeres anglosajonas, especialmente de las de la aristocracia. Las nuevas costumbres denotaban status más que afiliación religiosa. Sin embargo, a pesar de las reformulaciones que se evidencian en cuanto a las tradiciones, Blair sostiene que no se puede negar la supervivencia de la magia: en la Europa altomedieval existían multitud de adivinos, hechiceros, videntes y mujeres sabias y no hay razón para pensar que en esta región insular fuese diferente (Blair, 2005, p. 170). Para bien o para mal, la Iglesia tuvo que lidiar con ellos. En todo caso, nos interesa analizar si hubo mutua tolerancia e influencia en esta relación o un abismo entre ambas culturas.

En este sentido, debemos tener en cuenta que muchos de los valores y prácticas anglosajonas entraban de algún modo en conflicto con las enseñanzas cristianas y con quienes inicialmente decían sostener una comprensión de la naturaleza del Dios cristiano, aunque en realidad fuera probablemente una apropiación sincrética (Dunn, 2009, p. 135). Uno de esos problemas tuvo que ver con la relación del cristianismo con los guerreros, aquellos optimates que rodeaban y dependían de su líder. No estaba garantizada una buena relación de estos personajes con la nueva religión, tal como se constata a partir del Poenitentiale atribuido a Teodoro de Tarso 
(PT I, i, 5, 184) en donde se determinaban las penitencias correspondientes a los diferentes pecados que atentaban contra la vida del buen cristiano. ${ }^{10}$ La elaboración de esta fuente y otras, como las epístolas de Alcuino y de Bonifacio, evidencian las dificultades que encontró la Iglesia para controlar la deposición de las armas o los excesos en las fiestas y celebraciones entre los guerreros, muchas de ellas vinculadas a rituales paganos que se realizaban en diferentes sitios del paisaje que se consideraban sagrados (Blair, 2018, p. 97).

Otro problema lo constituyó la pervivencia del concubinato, el matrimonio serial y el matrimonio dentro de grados de parentesco prohibidos, los cuales eran aún comunes. Atacando la práctica del concubinato la Iglesia estaba lanzando un ataque a una institución social muy importante, porque la concubina era parte de la familia y sus hijos podían heredar del padre si este así lo quería. Este avance pudo considerarse demasiado intrusivo y pudo haber contribuido a retrasar la expansión del cristianismo entre la población (Dunn, 2009, p. 138; Yorke, 2003, p. 175).

\section{Mujeres activas, mujeres protagonistas}

En virtud de lo expuesto, merece especial atención el rol de las mujeres en esta sociedad en proceso de cristianización. En los estamentos altos de las dinastías gobernantes era reconocido su papel para mantener la influencia familiar a través de la dirección de monasterios o como agentes fundamentales para la conversión de sus esposos paganos (Blair, 2005, pp. 42 y 85; Schneider, 1985, pp. 243-252). Entre otras actividades, la participación femenina en el proceso de difusión del cristianismo estuvo vinculada con sostener el avance de los misioneros a través de la oración y la provisión de libros, como lo revelan las cartas de San Bonifacio a diferentes monasterios femeninos (Wood, 2008; Yorke, 1998). Pero además de aquellas que formaban parte de las congregaciones religiosas, las hagiografías nos presentan el papel destacado de princesas cristianas casadas con reyes paganos que favorecieron su conversión, como lo fuera el caso de Bertha, esposa de Ethelberto de Kent, y de su nieta casada con Edwin, rey de Northumbria (Wood, 2008).

En este sentido y en la búsqueda de una explicación al aumento de las sepulturas femeninas con ajuares para el siglo VII, Helena Hamerow ha propuesto que el pequeño número de abadesas y monjas reales que figuran preponderantemente en los registros escritos del período de la conversión fue parte de un gran e indocumentado cambio en el rol de la mujer que comenzó varias décadas antes de la fundación de los primeros monasterios femeninos. Ha sostenido también que estas tumbas con ricos ajuares reflejan una nueva investidura en la conmemoración de mujeres que vienen a representar sus intereses familiares en patrimonios adquiridos recientemente y cuya importancia era destacada por su capacidad para conferir legitimidad sobrenatural en la afirmación dinástica (Hamerow, 2016, pp. 423-447).

10 En relación a las penas establecidas en los penitenciales, en los siglos estudiados no habrían implicado castigo físico o privación de la libertad sino que tenían que ver con la alimentación, vigilias o determinadas privaciones (Neyra, 2006). En general, se establecían ayunos, aunque las características, duración y modalidad del mismo varía según los textos. Se suponía que el momento de la confesión debía ser fruto de una elección libre y espontánea, y el proceso de penitencia hasta la absolución definitiva privado y secreto (Mc. Neill y Gamer, 199o). Los autores aquí citados interpretan que el objetivo de los penitenciales tuvo que ver con una intención educadora por parte de la Iglesia para rehabilitar y curar el alma del pecador y así favorecer la relación de este con Dios y la sociedad. Por mi parte, considero que, si bien este análisis es muy posible y acertado, no debemos perder de vista que, como ha señalado Thomas Oakley (1940), estos textos fueron muy importantes al momento de complementar las leyes seculares y contribuir así al establecimiento del control y castigo por parte de las autoridades tanto eclesiásticas y como laicas. 
La adquisición de tierras y bienes por parte de las mujeres miembros de las familias reales se vinculaba estrechamente con el proceso de cristianización, ya que los reyes no solo donaban tierras a la Iglesia en favor de sus almas sino que la fundación de monasterios era parte del proceso de consolidación territorial de las casas reales. Especialmente las donaciones se realizaron a mujeres de las familias reales que no eran consideradas necesarias para las alianzas matrimoniales o las urgencias militares de los diferentes reinos. La abadesa Aelffled, hermana del rey Egfrido, es un ejemplo de estas mujeres a cargo de casas monacales y vinculadas estrechamente con la familia gobernante. ${ }^{11}$ Asimismo, Aebbe, hermana del rey Oswiu y abadesa del convento Coldingham, aparece como personaje importante en la Vida de San Wilfredo, ya que fue quien advirtió al rey Egfrido del peligro de haber encarcelado al santo y haber tomado su relicario, el cual había provocado la enfermedad de la reina (VW, XXXIX).

Dotar a una casa-doble siguiendo el modelo franco en donde se alojaban aquellas reinas que habían enviudado o aquellas princesas sujetas a las estrategias de sus padres que hacían preferible tal opción a la del matrimonio ofrecía una alternativa de sostén material y social para estas mujeres aristocráticas. Generalmente, quienes dotaban a tales monasterios eran los parientes de sangre de las viudas y no los vinculados por matrimonio; para el caso de las princesas podían ser tanto sus parientes maternos como paternos (Blair, 2005). Desde tal posición, estas esposas de Cristo podían tejer redes de influencias y establecer su control territorial como las esposas seculares. Operando desde un monasterio central, una abadesa real podía ser guardiana de su historia familiar y de los cultos mortuorios vinculados a su parentela a la vez que ejercer un considerable poder en su nombre. Especialmente dinastías como las de Kent, Northumbria y Mercia fundaron redes de abadías reales regidos por sus hijas, hermanas o tías fundadoras (Schneider, 1985).

Por el contrario, la relación de las mujeres de los estamentos bajos de la sociedad con la Iglesia no parece haber sido tan sencilla. Las dificultades en torno a la existencia e identidad de las diosas anglosajonas, especialmente las "madres" mencionadas por Beda en Modranecht (Meaney, 1985, pp. 1-29), nos dan algunos indicios de los problemas vinculados al intento de establecer el rol de la mujer en el paganismo anglosajón y a su reacción al arribo de la nueva religión. Si, como su nombre lo sugiere, estas "madres" eran seres femeninos sobrenaturales particularmente asociados con el nacimiento, la fertilidad y los asuntos domésticos, es probable que haya sido difícil para la Iglesia desalentar creencias populares y rituales cotidianos vinculados a ellas. El silencio prácticamente total de las fuentes escritas acerca de las mujeres no aristocráticas y seculares es roto con algunos pocos ejemplos de penas en Poenitentiale que parecen indicarnos que estas mujeres eran las más reticentes a abandonar las viejas prácticas, como colocar niños en el techo de sus casas o en los hornos para curar la fiebre, acompañado de la recitación de encantamientos, la ingestión de alimentos sacrificados como ofrendas o el uso del semen del marido o de su sangre para elaborar afrodisíacos o medicinas (PT I, xiv, 15-16, 196-197).

De esta manera, la Iglesia fue alienando progresivamente a las mujeres, estableciendo penitencias y períodos de purificación no solo para modificar tales comportamientos sino también para regular su participación en la liturgia, por ejemplo, impidiendo comulgar a quienes hubiesen dado a luz recientemente o se encontraran en su período menstrual (HE I, 27). Al no considerarse entre los anglosajones las mismas nociones de impureza, Dunn entiende que tales prescripciones contribuyeron a alejar a buena parte de las mujeres de la Iglesia (Dunn, 2009, p. 140).

11 "et beata Aelfleda abbatissa, semper totius provinciae consolatrix optimaque consiliatrix". VW, LX, VCA, III, 6, VCP, XXIII. 


\section{Casos hagiográficos}

Las hagiografías estudiadas reflejan con claridad que una estrategia muy importante llevada adelante por la Iglesia para avanzar en el proceso de conversión fue santificar a miembros de los distintos linajes anglosajones, de familias de la élite, algunas descendientes de importantes jefes querreros, como en el caso de Guthlac (VG, I-IV), y otras fundadoras de santuarios y monasterios (mynsters) que fueron ocupando el paisaje de los distintos reinos. De esta manera, no solo se alentaban donaciones, sino que también se proveía un modelo y un centro de devoción religiosa para las poblaciones locales (Yorke, 2003, p. 174).

Los textos manifiestan este objetivo a partir del relato de diferentes sucesos que fundamentaban y otorgaban legitimidad al patrono respectivo de cada comunidad. De esta manera, las vitae se han ocupado no solo de describir el origen y nacimiento, hasta la orquestación de funerales de sus protagonistas, sino también de dar cuenta con lujo de detalle de aquellos milagros que otorgaban autoridad al santo venerado y a su santuario.

En nuestras fuentes, el proceso por el cual son santificados Guthlac, Cutberto y Wilfredo se inicia en sus funerales, en donde se llevan adelante una serie de rituales que tuvieron como práctica común el lavado del cuerpo y su preparación para la sepultura. Las ceremonias de traslado, las misas subsiguientes, la constatación y exposición del cuerpo incorruptible en el caso de Guthlac y Cutberto y la enumeración de gran cantidad de milagros posteriores al fallecimiento de cada uno de estos hombres santos nos señalan la intencionalidad y la importancia que tenía para los monasterios el asegurar la santificación de sus referentes (VCA, IV, 13-18; VCP, XL-XLVI; VW, LXV-LXVIII; VG, LI).

También se evidencia en ellas que el control y la administración del culto estaba en manos del monasterio, como lo demuestra el caso del muchacho endemoniado mencionado en las dos vitae de Cutberto. En este suceso, se relata que ante el intento infructuoso de sanarlo utilizando las reliquias de los mártires que Lindisfarne poseía, un sacerdote de este monasterio decide darle de beber al joven una infusión con tierra del sitio en donde se había vertido el agua que se había utilizado para lavar el cuerpo del fallecido obispo. Luego de haber expulsado al demonio, el muchacho y su padre se dirigieron al monasterio para rendir culto a las reliquias de los mártires y dar gracias en el lugar en donde el suelo había sido santificado por el agua de aquel baño. El sitio de donde se tomó la tierra había sido preservado en forma de fosa o pozo delineado con maderas y recubierto con piedras. Al estar cercano a la sepultura, funcionaba como un santuario secundario que realzaba al principal y era resguardado de igual modo por la abadía, por lo que no era de fácil acceso (VCP, XLI). En su texto, Beda adelanta que antes de su muerte Cutberto había declarado que esperaba ser visitado en su sepulcro por los hermanos de Lindisfarne, a la vez que les advertía de los peligros que su santuario podría ocasionar si resultaba fácilmente accesible a diferentes tipos de visitantes que posiblemente atraería y los exhortaba a tomar los recaudos pertinentes para evitar actos vandálicos o un uso no cristiano (VCP, XXXVII). Retomaremos este aspecto más abajo.

Por su parte, Felix relata en su Vita Sancti Guthlaci que el protagonista eligió como sitio para retirarse a la vida ascética la isla de Crowland, ubicada en las marismas (Fens) al este del actual territorio inglés. Según el hagiógrafo, este era un lugar desolado y

12 "Qui ubi tota fratrum caterua astante, uidente, et congratulante ad reliquias martirum genibus flexis dedir laudem Deo Domino et Saluatori nostro lesu Christo, iam et ab hostis uerbere liberatus, et in fide firmior quam fuerat effectus, ad propria rediit". VCP, XLI; VCA, IV, 15 . 
deshabitado debido a los fantasmas de los demonios que encantaban el lugar. ${ }^{13}$ En aquel sitio había un antiguo túmulo y sobre él Guthlac construyó su refugio en el cual habitó y llevó adelante su vida de eremita (VG, XXVIII).

La idea de que un sitio u objeto sagrado detentaba poderes sobrenaturales está estrechamente vinculada con las creencias antiguas anglosajonas sobre las que hemos hecho mención, especialmente por sus atributos o efectos apotropaicos, es decir, la eficacia de ciertos lugares y sustancias para producir curas, proporcionar protección o asegurar fecundidad para la tierra. Pareciera que, en sus inicios, el culto a los santos anglosajones, a sus sepulcros y a sus reliquias se pareció bastante a las prácticas curativas y apotropaicas relacionadas con antiguos sitios sagrados y amuletos, que tomaron luego la forma de relicarios (Dunn, 2009, p. 149). La Iglesia, a través de los textos hagiográficos, intentó reformular y restablecer cuáles eran esos sitios, elementos y objetos con el fin de controlar así las manifestaciones milagrosas y con la intención de enfatizar que los mismos eran obras del Dios cristiano.

Se creía que estos sitios y objetos sagrados detentaban poderes de bendición o maldición según quiénes y con qué intenciones se acercaran a ellos. En efecto, además de la advertencia de Cutberto respecto a los visitantes de su sepulcro, Esteban de Ripon relata que, en cierta ocasión y sin motivo alguno aparente, la casa en donde Wilfredo murió, ubicada en el monasterio de Oundle, y el sitio en el cual se produjo el lavaje de su cuerpo fueron atacados por un incendio provocado por un grupo de nobles. Durante este suceso, se produjo la aparición de un ángel que reprendió el accionar de los guerreros, a la vez que el fuego nunca tocó el lugar y luego se extinguió de forma milagrosa. A continuación, el relato describe que el castigo divino alcanzó a estos hombres que fueron cegados por la luz del día y posteriormente asesinados (VW, LXVIII). El mismo efecto tuvo el mencionado relicario robado a Wilfredo por la reina Iurminburg, quien había instigado el encarcelamiento del santo (VW, XXXIX). En este caso, el objeto habría sido utilizado como amuleto de protección según era costumbre entre las mujeres desde el período pre-cristiano, pero en el texto del hagiógrafo se le otorga un nuevo significado y nuevos poderes que provocan la enfermedad de la dama que pretendía mantener bajo control al obispo. Solamente cuando es devuelto a su dueño, se produce la sanación. De esta manera, aparecen en las vitae conexiones entre el imaginario popular y las nuevas formas de culto que intentaba imponer la Iglesia, a la vez que pone de manifiesto la intención de establecer la superioridad de la autoridad eclesiástica por sobre la realeza y la aristocracia laica.

Si bien es indudable que la inclusión de los relatos milagrosos tenía como objetivo generar un impacto favorable y de atracción hacia el culto por fuera de los monasterios, a la vez nos dice mucho acerca de la manera en que las élites de Northumbria presentaban el cristianismo que patrocinaban a un público más amplio. Decidir y encargar la escritura de estas historias fue un proceso significativo, que responde a la intención de elevar al obispo como santo patrono de una casa monacal vinculada a la realeza (VCA, II, 3, 6. IV, 10; VCP, 10, 23, 24, 34). En el caso de Cutberto, los sucesos de su vida fueron reunidos y transmitidos oralmente en este ambiente de élite, especialmente dentro de los grandes monasterios del reino, y luego escritos cuando se consumó el traslado a su santuario definitivo. El mismo fue uno de los primeros realizados en el territorio anglosajón y probablemente el primero en toda Northumbria (Thacker, 2016, p. 401). Tanto en la Vida Anónima como en la prosa de Beda se relata que en el momento de retirarlo de su sepultura original se produce

13 "Nullus hanc ante famulum Christi Guthlacum solus habitare colonus valebat, propter videlicet illic demorantium fantasias demonum, in qua vir Dei Guthlac, contempt hoste, caelesti auxilio adiutus, inter umbrosa solitudinis nemora solus habitare coepit". VG, XXV.

14 Sobre este tema ver los estudios de John Blair (2005). 
otro milagro que probaba la santidad del difunto: el cuerpo fue hallado incorrupto. ${ }^{15}$ Según se describe, la piel no se encontraba en descomposición y las extremidades permanecían flexibles lo que, en opinión de John Blair (2005) entre otros, se vincula con la práctica de embalsamamiento. Esta misma situación se repite en la Vida de Guthlac (VG, LI).

En las hagiografías analizadas aparecen, además, diferentes elementos del ambiente natural que eran considerados sagrados para el paganismo anglosajón y que están cargados de simbolismo. No solo el agua y la tierra eran consideradas fuentes de poderes sobrenaturales y resignificadas en los relatos milagrosos; también lo eran la aparición de determinados animales, ${ }^{16}$ el vuelo y el canto de los pájaros, las señales luminosas de astros o el arcoíris en el cielo. Estos fenómenos eran vinculados con prácticas de adivinación realizadas por hombres y mujeres considerados sagrados (Dunn, 2009, pp. 76-83). Son a estos mismos símbolos a los que el hagiógrafo de Wilfredo recurre para explicar que en el momento de su muerte se escuchó el batir de alas de pájaros que volaban hacia lo alto, en señal de que el alma del obispo era elevada al paraíso (VW, LXVI), o cuando describe el blanco arco de luz que apareció rodeando al monasterio y a la iglesia de San Pedro en donde descansaban sus restos, en señal de santidad y autoridad divina (VW, LXVIII).

\section{Relaciones y reacciones}

Si bien las fuentes centran su relato en la vida de cada santo y en el desarrollo de las relaciones de poder entre los monasterios que iban poblando el paisaje y las élites anglosajonas, también nos permiten observar ciertos aspectos de las relaciones que estas comunidades tuvieron con las poblaciones aledañas y aquellas aldeas campesinas que visitaban. Especialmente las vitae de Cutberto y Wilfredo dan cuenta de que los clérigos se trasladaban de un lugar a otro, predicando y visitando comunidades cercanas y lejanas a los monasterios. Beda relata que era costumbre de Cutberto visitar distintas aldeas y en tales ocasiones tuvieron lugar diferentes manifestaciones milagrosas, como la sanación de una monja realizada con la unción de aceite consagrado (VCP, XXX). O también la oportunidad en la que llegó hasta una serie de aldeas montañosas diseminadas en sitios "agrestes y lejanos" (montana et agrestia loca) (VCP, XXXII) Se nos narra que, en estos lugares, una multitud se congregaba para escuchar la predicación y obtener la bendición del obispo. Al no haber, según el texto, estructura eclesiástica alguna, los campesinos cortaron ramas del bosque cercano y prepararon una especie de tienda en donde el santo residió durante dos días, recibiendo a quienes se acercaban a él. En tal ocasión, una mujer llegó a pedir por la sanación de un joven gravemente enfermo el cual yacía en una camilla que había sido colocada a la orilla del bosque; se nos dice que a través del poder de la oración del obispo y de su imposición de manos el muchacho fue sanado lo que no había podido lograrse a través de los compuestos y medicinas preparadas en el lugar (VCP, XXXII).

Wilfredo, por su parte, luego de haber sido liberado de su cautiverio, llegó a las regiones meridionales de la isla, a la zona de Selsey, actual Sussex, en donde emprendió la tarea de predicar al monarca que aún no se había convertido. Se nos relata que fue bien recibido por este rey, el cual le permitió reunir a la población para que escuchara la enseñanza del evangelio. El hagiógrafo señala que esta

15 "Extremam autem indumentorum eius partem pro ostendendo incorruptionis signo tollentes, nam quae carni illius proxima aderant prorsus tangere timebant”. VCA, IV, 14; VCP, XLII.

16 Félix describe en su vitae que una serie de animales atormentaban al santo: un león, una serpiente, un toro, un oso, un lobo, jabalí, un buey, un caballo, un ciervo y un cuervo. VG, XXXVI. 
visita fue un éxito, ya que se logró bautizar a miles de paganos de ambos sexos en un solo día, habiéndolos exhortado de dejar de lado las prácticas idólatras. A partir de esta conversión, Wilfredo obtuvo una donación de 87 hides de tierra en Selsey, en donde fundó otra comunidad monástica que se sostuvo hasta después de su muerte (VW, XLI).

En ambas historias se ponen de manifiesto las estrategias de los eclesiásticos al transmitir su mensaje para que fuera aceptado por las distintas comunidades. Más allá de lo verídico o no del relato y de las exaltaciones, por momentos exageradas, de los logros de los protagonistas, lo que nos interesa es observar algunos detalles que aparecen mencionados. En el caso de Cutberto, es evidente que para el momento en que se escribe la fuente aún quedaban muchos poblados campesinos en sitios remotos que no habían sido alcanzados por la cristianización. En esta oportunidad, se hace referencia al bosque como un lugar importante, ya que de allí se tomaron los recursos que se utilizaron para el refugio del santo, es en donde se sitúa al muchacho enfermo y es desde donde provenía la mujer que acude al visitante, a la vez que se destaca la inutilidad de los remedios y preparados con los que se lo intentó sanar en el lugar.

Como vimos, el bosque era considerado un espacio sagrado para el paganismo anglosajón, era el sitio en donde tenían lugar diferentes cultos y prácticas vinculadas con las creencias antiguas. Se suponía que era habitado por elfos, hadas, distintas deidades y entidades sobrenaturales. La mayoría de estos rituales eran realizados por mujeres, quienes detentaban el conocimiento para la preparación de medicinas, así como la ejecución de encantamientos o ritos de adivinación que se vinculaban con la sanación, la fertilidad o las buenas cosechas (Dunn, 2009, pp. 74-76, 138-141). Como señalamos, la relación entre la Iglesia y las mujeres campesinas no era sencilla debido a la resistencia que oponían a abandonar esas antiguas costumbres y prácticas. A diferencia del rol prominente que tuvieron algunas mujeres aristocráticas, aquellas que se encontraban por fuera de las élites fueron cuestionadas, desvalorizadas y posteriormente sancionadas por el cristianismo. El Penitencial de Teodoro de Tarso da cuenta de esta situación en la cual se alienta, por ejemplo, a los esposos cristianos a desestimar a su mujer no cristiana en caso de que continuara con la adoración de los ídolos y las prácticas paganas, además de desalentar la práctica del concubinato (PT, II, xii, 18-19).

La estrategia desplegada en la Vida de Cutberto entonces no es la de prohibir la utilización de las medicinas o rituales caseros sino destacar la inutilidad de la intervención de la mujer en la cura del joven, al quedar demostrada la superioridad del poder divino que actuaba a través del santo. Esto mismo ocurre con los habitantes del sur de la isla convertidos por Wilfredo, a quienes se los habría convencido de las ventajas de dejar de lado la idolatría, lo que trajo aparejado distintas victorias militares para su rey Ceadwalla frente a sus vecinos y el fin de una sequía que se había prolongado por tres años (VW, XLI; HE, IV, 13).

Por otra parte, desde los inicios de la misión católica en Kent, el papa Gregorio había aconsejado a Agustín de Canterbury que se construyeran iglesias en sitios paganos que se consideraban sagrados y que se establecieran los días de celebraciones cristianas en los mismos que ocupaban las festividades tradicionales (Dunn, 2009, p. 147). De esta manera, los antiguos santuarios eran resignificados, vinculándolos a una divinidad que se consideraba superior, sin perder su status de poder. De alguna manera, ese poder sagrado era compartido por ambas formas religiosas (Hayden, 2002, pp. 205231). Pero a la vez se producía una especie de solapamiento de los espacios y símbolos que representaban a ambas creencias. Cambiaba, en todo caso, quién controlaba esos lugares, cómo se administraba el culto, a quién o quiénes se dirigía y cómo se 
representaba visual y sensorialmente. ${ }^{17}$ Hemos observado anteriormente cómo los amuletos y colgantes que se hallaron en algunas tumbas con ajuares presentaban diseños cruciformes. También mencionamos el relicario de Wilfredo que atrajo a la reina Iurminburg. Estos objetos son claros ejemplos de cómo fueron sintetizándose los elementos que representaban lo sagrado; no se prohibía el uso de amuletos y colgantes como instrumentos protectores sino que, en todo caso, fueron reelaborados a través del imaginario cristiano con sus propios símbolos, transformándose en portadores de reliquias en lugar de contener dientes de animales o distintos tipos de hierbas.

Otro ejemplo que nos brinda la arqueología es la cruz dedicada a la abadesa Ethelburga, quien según relata la vita de Wilfredo habría acompañado a la abadesa Elfflaed de Whitby al lecho de muerte del rey Aldfrith en 705 (VW, LIX). Los fragmentos de este monumento realizado en piedra fueron hallados en la iglesia de Hackness en el actual condado de North Yorkshire. La cruz presenta diseños cristianos con la figura central de la santa a quien está dedicada y una serie de epitafios en latín. Estos aparecen combinados con simbología y representaciones paganas, como lo son los nudos celtas y las ornamentaciones de plantas, flores y animales. Además, se ha propuesto como interpretación que la cruz plantada en la tierra representaba al árbol, una imagen central de la religión pre-cristiana, que habría sido reelaborada por el cristianismo y convertida en arbor vitae, árbol de la vida (Ó Carragáin, 2005, p. 286).

El cristianismo también tuvo que encontrar estrategias para convencer a las comunidades aldeanas de reemplazar a las divinidades y prácticas antiguas conectadas con el mundo natural en materia de protección de la vida y de las cosechas. Beda relata que en cierta ocasión Cutberto se hallaba visitando un monasterio a orillas del río Tyne al noreste de la isla cuando un grupo de monjes que intentaba cruzar el río en una balsa fue arrastrado por los fuertes vientos hacia la desembocadura del mar. Desde las orillas los compañeros de la abadía rezaban y suplicaban la ayuda divina, mientras algunos campesinos que observaban la escena se burlaban de la situación. Cutberto intervino sin éxito intentando apaciguar los insultos. Es interesante que el hagiógrafo destaca que los aldeanos expresaron claramente que ningún hombre iba a orar por el bienestar de aquellos monjes y deseaban que Dios no tuviese piedad de ellos porque les habían quitado a los hombres las antiguas maneras de adoración (ueteres culturas) y nadie sabía cómo debían realizarse las nuevas.

Es evidente que la instalación del monasterio había afectado la forma de vida y creencias de los habitantes del lugar. Claramente no eran bien recibidos. El malestar podría tener que ver con el impedimento de realizar los cultos y prácticas rituales que garantizaban las buenas cosechas, así como el bienestar y prosperidad de la comunidad (Dunn, 2009, p. 146). Finalmente, los monjes son salvados gracias a la intervención de Dios a través de la oración ferviente de Cutberto. El relato culmina declarando que a partir de este milagro los campesinos reconocieron la superioridad de la fe del santo y que inmediatamente revirtieron su actitud elogiando y alabando su accionar.

Observamos así que la nueva doctrina no fue sencillamente aceptada por las comunidades rurales; rituales como el bautismo de niños fueron resistidos con frecuencia (PT, I, xiv, 28-30, 197; II, iv, 5-11). Entre los anglosajones eran frecuentes las prácticas de abandono de niños no deseados, el aborto e inclusive el infanticidio (Dunn, 2009, p. 142).

17 Respecto a esta situación, Keith Thomas (1991) señalaba en su texto ya clásico que la apelación al uso de la magia y de poderes sobrenaturales fue un elemento esencial en el avance de la Iglesia anglosajona sobre el paganismo. Los misioneros no dudaron en contraponer y enfatizar la superioridad de las oraciones de los cristianos frente a los encantamientos de los paganos, intentando así monopolizar el control sobre los milagros, sitios y objetos considerados sagrados.

18 "At illi rustico et animo et ore stomachantes aduersus eum, Nullus inquiunt hominum pro eis roget, nullius eorum misereatur Deus, qui et ueteres culturas hominibus tulere, et nouas qualiter obseruare debeant nemo nouit”. VCP, III. 
Especialmente esto sucedía con aquellos infantes que nacían con algún tipo de discapacidad o en algunos casos, simplemente por ser niñas. Era común que se los rechazara o se los abandonara; si no eran rescatados y morían se creía que el alma retornaba al otro mundo o encontraba el camino para regresar en un niño aún no nacido (Dunn, 2009, p. 91). El Poenitentiale establece una serie de penas para quienes no bautizaban a sus hijos antes de los tres años, así como el código de leyes de Ine de Wessex (Whitelock, 1996, p. 364). Todo parece indicar que la Iglesia tuvo dificultades para desplazar las antiguas costumbres y creencias sobre los espíritus de quienes acababan de llegar a este mundo e imponer el bautismo infantil, especialmente porque este se contraponía a aquellas prácticas sobre los muertos cuyas almas debían ser transportadas en dirección opuesta.

Esta situación se manifiesta en nuestras fuentes en el momento en que Wilfredo visitaba cierta ciudad mencionada como "On Tiddanufri" cumpliendo con sus tareas de obispo. En esa ocasión, una mujer se acercó al santo gimiendo y suplicando por un milagro. Llevaba en brazos a su hijo recién nacido ya muerto, ocultándolo de la vista del público. Al darse cuenta de que el niño ya no tenía vida, Wilfredo dudó de su proceder, pero la mujer insistió en que se lo bautizara porque creía que de esa manera recuperaría la vida. Así, el obispo accedió y posó sus manos sobre la criatura, que en ese instante volvió a vivir. Después, le practicó el bautismo y se lo devolvió a su madre requiriéndole entregarlo al servicio de Dios cuando cumpliese siete años. La fuente relata que viendo la mujer la belleza de su hijo y siguiendo los consejos "malvados" de su esposo, decidió faltar a su promesa y huir del lugar. Aún así, fue perseguida por el alguacil de Wilfredo, quién los encontró escondidos entre los de "etnia británica" (aliis Bryttonum). El niño fue tomado por la fuerza para ser entregado al monasterio de Ripon, en donde se lo educó y se le dio el nombre cristiano de Eodwald, siendo conocido como el "hijo del obispo" (filius episcopi) (VW, XVIII).

De este episodio se desprenden varias consideraciones. Por un lado, pareciera que hubo problemas para comprender el significado y el alcance del bautismo. Sally Crawford ha propuesto como hipótesis que el bautismo fue malinterpretado popularmente, especialmente para ser aplicado a niños que estaban al borde de la muerte, y que inclusive se sostenía la idea de que no era necesario para aquellos infantes vivaces, creencia que perduró por largo tiempo inclusive hasta la Edad Media Central (Crawford, 1999, p. 339-353). Aparentemente esto respondía a la idea extendida entre los anglosajones de que las almas de los niños se encontraban en una situación liminal, es decir, no se encontraban ni en este mundo ni fuera de este, estaban en un lugar incierto, de frontera, y por lo tanto podían pasar con facilidad de un lugar a otro e ir y venir de la vida a la muerte (Dunn, 2009, p. 90). Inclusive los cuerpos de los niños eran depositados en lugares diferentes y alejados de las sepulturas de los adultos. Se han encontrado en diferentes sitios liminales como zanjas, cunetas, acequias, pasajes, caminos o debajo de pisos de viviendas, ya que se consideraba que sus espíritus podían regresar rápidamente al mundo desde donde provenían o ingresar a un nuevo feto y generar otra vida (Dunn, 2009, p. 91).

Probablemente la mujer del relato apeló al bautismo como a un ritual que se vinculaba a la vida y, por lo tanto, que podía regresar de la muerte a su hijo. Evidentemente no comprendía el significado cristiano del mismo, cargado del simbolismo de pertenencia a la Iglesia, vinculado con el perdón del pecado original y con la consecuente posibilidad del acceso de los niños al paraíso, en el caso de su muerte. Pero la fuente se encarga de diferenciar las creencias y es por eso que, en un principio, al constatar que el niño había fallecido Wilfredo duda en intervenir y que solo después de devolverle la vida milagrosamente practica el ritual.

Por otra parte, puede resultar llamativo para el lector actual el pedido del obispo y la posterior persecución de la familia para que entregase a la criatura para su formación 
y servicio. Sin embargo, hallamos que esta estrategia fue comúnmente utilizada por la Iglesia. Por un lado, es evidente que tanto Cutberto como Wilfredo ingresaron a sus vidas monacales desde muy temprana edad. Wilfredo lo hizo con tan solo 14 años y se nos dice que Cutberto sintió el llamado al servicio divino a la edad de 8, cuando se consideraba, según Beda, que finalizaba la niñez y comenzaba la juventud (VCA, II, 1; VCP, I; VW, p. II). Pero además encontramos que desde antes de los inicios de la misión a Kent el papa Gregorio Magno solicitaba el envío a sus dominios francos de jóvenes anglos de entre 17 y 18 años, aún no conversos, para ser ubicados en distintos monasterios de la Galia y puestos al servicio de la Iglesia (Greg I Ep, VIII-XIV, CCSL, vol. CLXa, pp. 378-379). Si los niños y jóvenes eran tomados por la fuerza, como queda manifestado en la Vida de Wilfredo, resulta lógico pensar que se generaran actitudes de resistencia y rechazo entre las comunidades campesinas a la introducción del cristianismo en sus territorios.

Nuevamente aparece en el relato la imagen de la mujer campesina como transgresora, resistiendo el avance de los clérigos que intentaban apropiarse de su hijo. No es casualidad que otra estrategia utilizada por la Iglesia para desalentar a la población a recurrir a las prácticas tradicionales ejercidas por las mujeres tuviese que ver con la introducción de un nuevo modelo de mujer a través del establecimiento del culto a la Virgen María (Dunn, 2009, p. 140). Efectivamente, Esteban de Ripon manifiesta en su relato que cuando Wilfredo regresaba de Roma en 705 cayó enfermo. Luego de varios días de padecimiento, tuvo una visión del arcángel Miguel que le anunciaba que iba a sobrevivir gracias a la intercesión de la madre de Dios. Al mismo tiempo, en esta aparición el ángel le reclamaba al obispo que ninguna de las iglesias que había construido estaba dedicada a quien intercedía por su vida, mientras que sí se habían levantado para algunos santos como Pedro y Andrés. Así fue que, luego de su recuperación, el santo decidió dedicar una iglesia a María en Hexham (VW, LVI).

El interés por difundir el culto a la Virgen se vinculaba con el intento de proveer una alternativa a la veneración de las antiguas deidades femeninas, puesto que resultaba una figura fácilmente identificable a la vez que protectora (Stoclet, 2007, p. 136). Pero al mismo tiempo se buscaba establecer la superioridad del modelo de mujer cristiana que proporcionaba María frente a las intervenciones de las mujeres en los rituales sagrados tradicionales (Dunn, 2009, p. 141). El rol que se le asignó como Theotokos, mensajera de Dios, en los debates teológicos del siglo IV presentaba la idea de la encarnación de manera equilibrada, lo que permitió otorgarle un status similar al de una diosa. De hecho, en la tardoantigüedad su culto había surgido de la veneración a deidades paganas femeninas, especialmente en Asia Menor en donde los cristianos se manifestaron más sensibles a representar el aspecto femenino de Dios (Benko, 1993, p. 229-265).

\section{Conclusiones}

En virtud del recorrido realizado, consideramos que estamos en condiciones de sostener algunas interpretaciones. Primeramente, no podemos negar la importancia de las hagiografías como fuentes sumamente relevantes para la reconstrucción histórica del período medieval, más allá de las dificultades y limitaciones del género. En especial, en los casos abordados notamos que, además de proveer un modelo de comportamiento cristiano a partir del relato de la vida de los santos, jugaron un rol fundamental a la hora de favorecer la consolidación de las diferentes casas monacales y santuarios a los cuales pertenecían sus referentes. Fueron instrumentos que no solo registraron las vicisitudes y problemas del período en los que se vieron involucrados 
sus protagonistas sino que favorecieron la atracción de la población hacia las distintas abadías, tanto para quienes acudían a ellas para formar parte de la congregación como de quienes visitaban los espacios sagrados como creyentes.

En este contexto, no es casualidad que las comunidades rurales aparezcan como escenarios en donde se desarrolla la actividad milagrosa de los hombres santos, especialmente si tenemos en cuenta que estas dependían de los poderes locales, originalmente laicos y progresivamente eclesiásticos. Al mismo tiempo, en el marco de una sociedad altomedieval, campesina, guerrera e iletrada, resultaba fundamental para las élites contar con el acceso a la mano de obra rural junto con sus excedentes, por lo que es comprensible que la nueva religión buscase consolidar su presencia en las tierras que procuraba convertir para garantizar así su reproducción. En consecuencia, cobra sentido que el santo sea presentado en los textos como un referente cohesionador de los diferentes grupos sociales, beneficiando con sus acciones milagrosas a todos los que acudían a él con fe.

Sin embargo, observamos que este acercamiento al campesinado no fue una tarea simple. La Iglesia necesitó adecuar sus estrategias a la realidad de las creencias tradicionales anglosajonas. El paganismo no fue erradicado de forma absoluta sino que persistía y resistía en los ritos, costumbres y tradiciones que aún se llevaban adelante y de los que a menudo se ocupaban las mujeres campesinas. Las fuentes abordadas dan cuenta de esta realidad, sobre todo cuando constatamos que estas mujeres que estaban por fuera de la élite fueron puestas en cuestión, junto con sus prácticas y creencias. De todos modos, si bien nuestros documentos nos aportan escasos indicios de las reacciones y resistencias campesinas, la apoyatura arqueológica y otras fuentes eclesiásticas nos han permitido observar que tanto en el arte, en las representaciones simbólicas, en los rituales, así como en los objetos, elementos y espacios considerados sagrados, lo pagano estaba allí presente, aunque de alguna manera solapado. Los diseños cruciformes intercalados entre nudos celtas, representaciones de flora y fauna, la cruces en piedras plantadas como árboles, la apelación al uso de la tierra o el agua, la observación de la luz, de las manifestaciones del cielo, la alusión a los animales, etc. Todos esos elementos nos señalan que el cristianismo anglosajón se forjó en estrecha relación con las creencias antiguas de las cuales no pudo deshacerse definitivamente. 


\section{Dibliografía}

"Alfayé Villa, S. (2009). Santuarios y rituales en la Hispania Céltica. Oxford: Archaeopress.

" Abrams, L. (2008). Germanic Christianities. En T. Noble y J. Smith (Eds.), The Cambridge History of Christianity, Volume 3, Early Medieval Christianities, c. 600 - C. 1100 (107-129). Cambridge: Cambridge University Press.

"Baños Vallejo, F. (1989). La Hagiografía como género literario en la Edad Media. Tipología de doce Vidas individuales castellanas. Oviedo: Departamento de Filología Española.

"Benko, S. (1993). The Virgin Goddess: Studies in the Pagan and Christian Roots of Mariology. Londres: Brill.

» Blair, J. (2005). The Church in Anglo-Saxon Society. Nueva York: Oxford University Press.

"Blair, J. (2018). Building Anglo-Saxon England. Princeton: Princeton University Press.

" Brown, P. (1997). El primer milenio de la cristiandad occidental. La construcción de Europa. Barcelona: Crítica.

» Capps, E., Rouse, W. H. D., Post, L. A. y Warmington, E. H. (Trads.). (1930). Historia Ecclesiastica Gentis Anglorum, Baedae De Venerabilis. Londres: The Loeb Classical Library.

" Castellanos, S. (2004). La Hagiografía Visigoda. Dominio social y proyección cultural. Logroño: Fundación San Millán de la Cogolla.

"Charles-Edwards, T. M. (1995). The Penitential of Theodore and the ludicia Theodori. En M. Lapidge (Ed.), Archbishop Theodore, Commemorative studies on his life and influence (141-74). Cambridge, Cambridge University Press.

»Charles-Edwards, T. M. (2008). Beyond the Empire II: Christianities of Celtic People. En T. Noble y J. Smith (Eds.), The Cambridge History of Christianity, Volume 3, Early Medieval Christianities, c. 600-c. 1100. (86-107). Cambridge: Cambridge University Press.

" Colgrave, B. (1927). The Life of Bishop Wilfrid by Eddius Stephanus. Cambridge: Cambridge University Press.

» Colgrave, B. (2007 [1940]). Two Lives of Saint Cuthbert. A Life by an Anonymous Monk of Lindisfarne and Bede's Prose Life. Cambridge: Cambridge University Press.

》 Colgrave, B. (1959). Felix's Life of Saint Guthlac. Cambridge: Cambridge University Press, 1956.

" Crawford, S. (1999). Children, Death and the Afterlife in Anglo-Saxon England. En C. Karkov (Ed.), The Archaeology of Anglo-Saxon England. Basic Readings (83-92). Nueva York y Londres: Garland.

"Crawford, S. (2004). Votive Deposition, Religion and the Anglo-Saxon Furnished Burial Ritual. World archaeology, 36(1), 87-102.

»Delehaye, H. (1962). The Legends of the Saints. Nueva York: Fordham University Press.

" Díaz, P. C. (2003). El cristianismo y los pueblos germánicos. En M. Sotomayor y J. Fernández Ubiña (Eds.), Historia del Cristianismo. Tomo I, El mundo Antiguo (687-759). Granada: Trotta.

"Dunn, M. (2009). The Christianization of the Anglo-Saxons C.597-c.700. Discourses of Life, Death and Afterlife. Londres: Continuum.

» Flechner, R. y Mhaonaigh, M. N. (Eds.). (2016). The Introduction of Christianity into the Early Medieval Insular World, Converting the Isles. Turnhout: Brepols. 
” Fouracre, P. (1990). Merovingian History and Merovingian Hagiography. Past E Present, $127,3-38$.

» García de la Borbolla, A. (1999). La hagiografía medieval, una particular historiografía. Un balance del caso hispano. Hispania Sacra, 51(104), 687-702.

» García de Cortázar, J. A. (2012). Historia religiosa del occidente medieval. Años 313-1464. Madrid: Akal.

» Hayden, R. M. (2002). Antagonistic Tolerance. Competitive Sharing of Religious Sites in South Asia and the Balkans. Current Anthropology, 43(2), 205-231.

» Hamerow, H. (2016). Furnished Female Burial in Seventh-Century England: Gender and Sacral Authority in the Conversion Period. Early Medieval Europe, 24(2), 423-447.

» Hamerow, H. (2002). Early Medieval Settlements. Nueva York: Oxford University Press.

» Meaney, A. L. (1981). Anglo-Saxon Amulets and Curing Stones. Oxford: British Archaeological Reports.

» Meaney, A. L. (1985). Bede and Anglo-Saxon Paganism. Parergon, 3, 1-29.

» Mitre Fernández, E. (1995). Historia de la Edad Media en Occidente. Madrid: Cátedra.

»Neyra, A. V. (2006). Los libros penitenciales: la penitencia tasada en la Alta Edad Media. Anales de Historia Antigua, Medieval y Moderna, 39, 1-9.

» Norberg, D. (Ed.). (1982). S. Gregorii Magni, Registrum Epistularum Libri VIII-XIV. Turnhout: Brepols.

» Oakley, T. (1940). The Penitentials as Sources for Mediaeval History. Speculum, 15(2), 210-223.

» Ó Carragáin, E. (2005). Ritual and the Rood: Liturgical Images and the Old English Poems of the Dream of the Rood Tradition. Toronto: The British Library and University of Toronto Press.

» Ó Carragáin, T. y Turner, S. (2016). Making Christian Landscapes in Atlantic Europe. Conversion and Consolidation in the Early Middle Ages. Cork: Cork University Press.

» O’Loughlin, T. y Conrad-O’Briain, H. (1993). The “Baptism of Tears” in Anglo-Saxon Sources. Anglo-Saxon England, 22, 65-83.

»Schneider, D. B. (1985). Anglo Saxon Women in the Religious Life: A Study of the Status and Position of Women in an Early Medieval Society. (Tesis doctoral), Universidad de Cambridge, Gran Bretaña.

»Stoclet, A. (2007). Consilia umana, ops divina, superstitio: Seeking Succor and Solace in Times of Plague, with Particular Reference to Gaul in the Early Middle Ages. En L. K. Little (Ed.), Plague and the End of Antiquity: The Pandemic of 541-750 (135-150). Cambridge: Cambridge University Press.

» Thacker, A. (2016). Shaping the Saint: Rewriting Tradition in the Early Lives of St. Cuthbert. En R. Flechner y M. N. Mhaonaig (Eds.), The introduction of Christianity into the Early Medieval Insular World. Converting the Isles, I (399-431). Turnhout: Brepols.

"Thomas, K. (1991). Religion and Decline of Magic. Studies in Popular Beliefs in Sixteenth and Seventeenth-Century England. Londres: Penguin Books.

"Watson, C. L. (2004). The Authority of Saints and Their Makers in Old English Hagiography. (Tesis de Doctorado en Filosofía), Universidad de Leicester, Gran Bretaña.

»Wood, I. (2008). The Northern Frontier: Christianity Face to Face with Paganism. En T. F. X. Noble y J. M. H. Smith (Eds.), The Cambridge History of Christianity. Early Medieval Christianities C. 600 - c. 1100 (230-249). Cambridge: Cambridge University Press. 
"Yorke, B. (1998). The Bonifacian Mission and Female Religious in Wessex. Early Medieval Europe, 7(2), 145-172.

"Yorke, B. (2003). Kings and Kingdoms of Early Anglo-Saxon England. Londres y Nueva York: Taylor \& Francis.

» Yorke, B. (2015). The Fate of Otherworldly Beings After the Conversion of the Anglo-Saxons. En C. Ruhmann y V. Brieske (Eds.), Dying Gods. Religious Beliefs in Northern and Eastern Europe in the Time of Christianization (167-177). Hannover: Die Publishing Company.

"Whitelock, D. (1996). English Historical Documents. Londres: Psychology Press.

"Wickham, C. (2016). The Comparative Method and Early Medieval Religious Conversion. En R. Flechner y M. Ní Mhaonaigh (Eds.), The Introduction of Christianity into the Early Medieval Insular World. Converting the Isles I (13-41). Turnhout: Brepols. 